\title{
História, trabalho e memória política. Trabalhadores rurais, conflito social e medo na Amazônia $(1970-1980)^{*}$
}

\author{
Regina Beatriz Guimarães Neto**
}

Resumo: Este artigo é resultado de pesquisas das múltiplas formas de trabalho na Amazônia sob a égide das políticas governamentais do regime civil-militar, instalado no Brasil em 1964. O texto contempla duas estratégias de análise: a primeira estuda os conflitos sociais na Amazônia relacionados às políticas e dispositivos governamentais que têm como interesse principal controlar a ocupação da terra pelos trabalhadores; a segunda privilegia registros diversos que testemunham a violência contra trabalhadores e conflitos no Araguaia, na área abrangida pela Prelazia de São Félix do Araguaia.

Palavras-chave: Amazônia; conflitos sociais; trabalhadores; ditadura civil-militar.

\begin{abstract}
This article presents the research results on multiple forms of labor in the Amazon under the aegis of government policies in civil-military regime launched in Brazil in 1964. The article embraces two strategies of analysis: 1- the social conflicts in the Amazon related to the policies and government institutions whose main interest was to control the land occupation occupied by the workers; 2- the importance of several records that witness violence against workers and the occurrences of conflicts in Araguaia in the area covered by the Prelature of São Félix do Araguaia.
\end{abstract}

Keywords: Amazon; social conflicts; workers; civil-military dictatorship.

* Este artigo é resultado de um conjunto de problemas e questões apresentado pela minha pesquisa, que conta com o apoio financeiro do CNPq (bolsista produtividade nível 2): “Memória e história plural: mundos do trabalho, territórios das migrações e microcosmos da violência. Entre práticas e relatos de trabalhadores do Centro-Sul e Nordeste e de lideranças sindicais em espaços da Amazônia." Agradeço a Maria Aparecida Martins Souza pela inestimável colaboração relacionada à pesquisa realizada na Prelazia de São Félix do Araguaia; um agradecimento a Joana Lucena pelo apoio ao levantamento documental e também às correções de Beatriz Schvartz. A leitura crítica de Antônio Torres Montenegro é como sempre insubstituível, suas sugestões e correções me permitem melhorar substancialmente o texto. Sou grata, ainda, às sugestões críticas de Antonio Luigi Negro.

** Departamento de História e do Programa de Pós-Graduação da Universidade Federal de Pernambuco. E-mail: reginabeatrizg@gmail.com 
Este artigo analisa um painel de experiências polimórficas dos trabalhadores rurais em áreas específicas da Amazônia' marcadas por conflitos agrários, durante o regime civil-militar, focalizando particularmente a década de 1970. A matéria dessas experiências, tão diferentes entre si, remete a um primeiro resultado dos estudos já realizados, com a produção de um "arquivo temático", análises e anotações diversas e documentos orais e escritos articulados entre si. São fragmentos que constituem fios específicos, com os quais se imbricam diversos modos de escrever acerca dos mundos do trabalho na Amazônia. É com eles, tendo-os como referência, que questiono a categoria trabalho, com as suas transmutações, ao designar tarefas inéditas, móveis e flutuantes.

Nesse tecido temático, reflito sobre as políticas governamentais que motivaram empresários a investir na Amazônia, estimulados pelos incentivos fiscais e também, simultaneamente, pequenos produtores e trabalhadores rurais a se deslocarem em busca de terra e trabalho. A intervenção do Estado, o monopólio do capital privado e a constituição de um mercado de trabalho bastante volátil constituem a base das relações entre os grandes proprietários de terra e empresários ${ }^{2}$ e os trabalhadores rurais. ${ }^{3}$ Os escritos de Octávio lanni, que resultam de suas pesquisas acerca da questão agrária na Amazônia, sintetizam essas relações antagônicas de maneira exemplar:

A prosperidade do capital e a força do Estado estão enraizadas na exploração dos trabalhadores do campo e cidade. Precisamente 'as vítimas das dificuldades agudas da fome, desnutrição, falta de habitação condigna e de mínimas condições de saúde'. ${ }^{4}$

1 Por meio de um dispositivo legal, a Lei 1.806 de 06.01.1953, estabelece-se que a Amazônia brasileira passe a ser denominada "Amazônia Legal”, criada pelo Plano de Valorização Econômica da Amazônia (sob a coordenação da SPVEA) e integrada pelos estados do Acre, Amapá, Amazonas, Mato Grosso, Pará, Rondônia, Roraima, Tocantins e parte do Maranhão (oeste do meridiano de $44^{\circ}$ ). Ao fazer referência ao território amazônico, as análises operam com a representação de território na perspectiva das práticas sociais e sua dimensão cultural. Ver SANTOS, Milton, especialmente: A natureza do espaço. Técnica e tempo. Razão e emoção. São Paulo: Hucitec, 1996; O Brasil: território e sociedade no início do século XXI. Rio de Janeiro: Record, 2001. Desde já, é preciso chamar a atenção para a necessidade de uma análise crítica dos esquemas interpretativos que têm como objetivo explicar e identificar a Amazônia como região (classificações arbitrárias que instituem identidades étnicas e regionais). Nessa perspectiva, consultar o texto do antropólogo ALMEIDA, Alfredo W. B. de. Antropologia dos archivos da Amazônia. Rio de Janeiro: Casa 8/ Fundação Universidade do Amazonas, 2008; e, também, SANTOS. O Brasil.

2 Grandes empresas, tradicionalmente oriundas do setor industrial e financeiro, como a Volkswagen, Bamerindus, Banco de Crédito Nacional-BCN (que dirigiu a Companhia de Desenvolvimento do Araguaia CODEARA), apenas para citar algumas mais emblemáticas, passam a investir no negócio da terra e do gado, desde finais da década de 1960, usufruindo dos incentivos fiscais a cargo da SUDAM (ao mesmo tempo em que fazem uso de modernas tecnologias, utilizam o recurso de trabalho escravo). Ver especialmente, ESTERCI, Neide. Conflito no Araguaia. Peões e posseiros contra a grande empresa. Petrópolis, RJ: Vozes, 1987; MARTINS, José de Souza. A política do Brasil: lúmpen e místico. São Paulo: Contexto, 2011; OLIVEIRA, Ariovaldo Umbelino de. A fronteira amazônica mato-grossense: grilagem, corrupção e violência. 1997. Tese (Livre docência). Departamento de Geografia, FFLCH-USP, 1997. Assinalo, também, a existência do Projeto Jari e sua fábrica de celulose, com de mais de três milhões de hectares de terras, situado entre os estados do Pará e Amapá, que utiliza mão de obra em condições subumanas de trabalho, ver PINTO, Lúcio Flávio. Jari: toda a verdade sobre o projeto de Ludwuig. São Paulo: Marco Zero, 1986.

3 A designação "trabalhador rural" indica a politização do uso desta categoria num determinado campo de relações de força, em que se configura a luta pela terra. A generalização torna-se importante ao possibilitar abranger diferentes segmentos ligados às atividades no campo. Pode-se considerar, desde pequenos proprietários, posseiros, trabalhadores assalariados e, até mesmo, trabalhadores não provenientes do mundo rural, ou que não se constituíram em sua história de vida na "lida ou labuta com a terra", mas que, ao migrarem para as áreas da Amazônia (ou outras áreas), envolveram-se diretamente na disputa pela terra, ligados a movimentos e entidades civis e religiosas, como o MST, a CPT, entre outros. Consultar, para essa importante discussão, o inovador trabalho de PEREIRA, Airton dos Reis. A luta pela terra no sul e sudeste do Pará. Migrações, conflitos e violência no campo. Tese (Doutorado em História). Programa de Pós-Graduação em História-UFPE, Recife, 2013.

4 IANNI, Octavio. A questão social. Revista USP/Superintendência de Comunicação Social da Universidade 
Não é fortuito o fato de a retórica do discurso do presidente Médici recair sobre os "deserdados" do Nordeste, apresentando a Amazônia como a solução para os problemas da seca e da "escassez de terra" (que deve ser entendida como concentração fundiária). Na reunião extraordinária da SUDAM (Superintendência do Desenvolvimento da Amazônia), ocorrida em outubro de 1970, anuncia o então general presidente:

Aquilo que não se pode fazer devido à escassez de capital pode ser feito com um programa integrado de colonização e de desenvolvimento, com um mínimo de recursos econômicos, capaz de gerar rapidamente a riqueza, para complementar, sem inflação, o esforço necessário à solução dos dois problemas: o homem sem terras no Nordeste e a terra sem homens na Amazônia [...]. Nessas condições, se impõem a expansão do setor agropecuário nas regiões favoráveis, o aproveitamento dos jazimentos minerais e a industrialização na medida necessária, bem como, ao mesmo tempo, a redistribuição dos seus excedentes demográficos, ocupando espaços internos vazios, mas potencialmente poderosos, sobretudo no território de atuação da SUDAM [...]. Estaremos, assim, facilitando o esforço de ocupação e desenvolvimento da Amazônia - imperativo do progresso e compromisso do Brasil com a sua própria História. ${ }^{5}$

A positividade política com que se apresenta a intervenção do governo militar, aliada à iniciativa privada, aparece como o pressuposto da legitimidade das ações a serem adotadas, com base em critérios objetivos dispostos a construir soluções para o problema social da terra, resultado direto de uma grande distorção demográfica. Assim, uma racional "redistribuição de populações" estimularia a ocupação e o desenvolvimento da Amazônia, assim como do Nordeste. A SUDAM, como instituição, passa a ter a força de um dispositivo político eficaz para cumprir esta "determinação de autoridade", orientada para o desenvolvimento e progresso do país. Por meio deste órgão reorienta-se a política de incentivos fiscais - que privilegiava antes as atividades industriais - para os projetos agropecuários, com o fim de atrair o empresariado a investir na Amazônia. Contudo, na concepção dos militares e dos empresários, não poderá haver progresso econômico sem "paz no campo", ou seja, sem controle social.

Uma das questões políticas mais importantes do regime instaurado em 1964, não apenas circunscrito à Amazônia, é a administração dos conflitos agrários, que devemsermapeados, controladose, dessaforma, alvo deintervenções pontuais. São tratados como assuntos de Estado, isto é, de governabilidade, numa configuração que articula novas estratégias de controle e segurança, subordinadas ao Conselho de Segurança Nacional (CSN), associadas ao novo modelo de desenvolvimento. Modelo este que se apoia em uma série de planos e programas governamentais, delimitados territorialmente e amplamente articulados entre si: Programa de Integração Nacional (PIN) - com a construção das rodovias Transamazônica e Cuiabá-Santarém -, Proterra, Polamazônia, Polocentro, Polonoroeste, entre outros. De acordo com o historiador Pere Petit:

de São Paulo, n 1, p. 145-154, citação à p. 147, 1989.

5 Ver MÉDICI, Emílio Garrastazu. Discurso do Presidente da República na Reunião Extraordinária da SUDAM (Manaus, 08/10/1970). A Amazônia Brasileira em Foco, $n^{\circ}$ 5. Rio de Janeiro: Comissão Nacional de Defesa e pelo Desenvolvimento da Amazônia, 1971, p. 15-6. 
A política econômica da Administração Federal na Amazônia Legal, desde a criação da Sudam até o fim do Regime Militar (1985), pode ser dividida em três fases diferentes, ainda que todas elas alimentadas pela ideia da Amazônia como território vazio a ser ocupado. A primeira foi pautada pela mudança na política de incentivos fiscais [...] Na segunda fase, entre 1970 e 1974, durante o mandato na Presidência da República do general Garrastazu Médici, foi dada a prioridade aos projetos de colonização na Transamazônica, aos projetos energéticos e à ampliação da rede viária terrestre [...] Na terceira fase, a partir de meados dos anos 70, o governo federal, em substituição ao modelo cepalista que inspirou as práticas da SPVEA e parte das desenvolvidas nos primeiros anos de existência da SUDAM, orientou sua intervenção econômica com base nas vantagens comparativas de que dispunha a Amazônia em relação a outras regiões do país, para contribuir ao desenvolvimento econômico nacional [...] durante o mandato na presidência da República de Ernesto Geisel (1974-1979), foi claramente definida qual seria a especialização econômica à qual seriam destinados os diferentes espaços intra-regionais da Amazônia brasileira, dando-se prioridade ao incremento da concentração fundiária e, sobretudo, aos investimentos destinados a criar a infraestrutura que demandavam os projetos mínero-metalúrgicos, além da escolha das áreas ou municípios da Amazônia Legal que seriam objeto de especial interesse do Programa de Pólos Agropecuários e Agrominerais (Polamazônia). ${ }^{6}$

Configura-se, desse modo, um processo de reterritorialização dos espaços, com políticas oficiais que se voltam para a classificação das diversas áreas, segundo interesses econômicos e políticos (estratégicos), instituindo grandes eixos de investimentos econômicos na Amazônia, denominados "polos de desenvolvimento", com apoio do capital nacional e estrangeiro.? Mas, fundamentalmente, esta "classificação de áreas" responde a uma lógica tecnocrática, que determina formas de intervenção política, a fim de exercer controle sobre os conflitos sociais. Órgãos de governo, muitas vezes, desencadearão ações de extrema violência, como foi o caso do Grupo Executivo de Terras do Araguaia e Tocantins (GETAT), no sul do Pará. ${ }^{8}$

Assinalam-se, ainda, nesse quadro, várias ocorrências em que forças repressivas do Estado e milícias privadas - de empresários e/ou fazendeiros - atuam em conjunto; e as fazendas/agropecuárias/núcleos de colonização/mineradoras

6 PETIT, Pere. Chão de promessas: elites políticas e transformações econômicas no estado do Pará pós-1964. Belém: Paka-Tatu, 2003, p. 81-2.

7 Ver ALMEIDA, Alfredo W. B. de. O conflito e mediação: os antagonismos sociais na Amazônia segundo os movimentos camponeses, as instituições religiosas e o Estado. 1993. Tese (Doutorado em Antropologia Social) - Museu Nacional, UFRJ, 1993; IANNI, Octavio. Colonização e contra-reforma agrária na Amazônia. Petrópolis: Vozes, 1979; A luta pela terra. Petrópolis: Vozes, 1978; Ditadura e agricultura (O desenvolvimento do capitalismo na Amazônia: 1964-1978). Rio de Janeiro: Editora Civilização Brasileira, 1979; ver também GONÇALVES, C. W. Porto. Geografia da violência no campo brasileiro: o que dizem os dados de 2003. Revista Crítica de Ciências Sociais, vol. 75, 2006; MARTINS, José de Souza. A política do Brasil: lúmpen e místico; do mesmo autor, A militarização da questão agrária no Brasil. Petrópolis: Vozes, 1984; OLIVEIRA, Ariovaldo Umbelino de. A fronteira amazônica mato-grossense: grilagem, corrupção e violência. 1997. Tese (Livre docência). Departamento de Geografia, FFLCH-USP, 1997; PEREIRA, Airton dos Reis. A luta pela terra no sul e sudeste do Pará; PETIT. Chão de promessas.

8 Ver ALMEIDA, Alfredo W. B. de. Getat - A segurança nacional e o revigoramento do poder regional. Boletim da Associação Brasileira de Reforma Agrária - ABRA, n², Campinas, 1981; FIGUEIRA, Ricardo Rezende. Pisando fora da própria sombra. Rio de Janeiro: Civilização Brasileira, 2004; PEREIRA. A luta pela terra no sul e sudeste do Pará. 
funcionam como verdadeiras cidadelas armadas por milícias, muitas vezes constituindo uma rede indistinguível entre empresários/fazendeiros, militares, agentes policiais e pistoleiros. ${ }^{9}$

O elemento histórico está na práxis, que se materializa no conjunto de ações, de saberes e medidas, que respondem a uma urgência: intervir nos conflitos sociais e não alterar a ordem fundiária do país. Na base das ações de violência política encontra-se a questão fundiária, é ela a pedra angular da garantia de controle da propriedade da terra ou do status quo da política agrária no Brasil. Expressa também uma das faces mais importantes das relações entre "militares" e "civis" (grandes empresários e proprietários de terra da Amazônia, representantes do poder judiciário e legislativo, entre outras categorias sociais).

Nesse cenário específico, em face da nova política governamental do regime civil-militar para a Amazônia, é que se deve historicizar os deslocamentos migratórios de trabalhadores, provenientes do Nordeste, Sul e das demais regiões brasileiras para a Amazônia, sobretudo a partir da década de setenta do século XX. Segundo Foweraker, citando informação de O Estado de São Paulo, em seu estudo sobre a luta pela terra na Amazônia:

Calcula-se que em toda a Região Amazônica há mais de 200 mil desses trabalhadores temporários, ou "volantes", vivendo em condições de desespero. ${ }^{10}$

Marcadas pela experiência de uma desterritorialização sem paralelo na história do Brasil, as redes migratórias que se constituem são referências cruciais para os estudos sobre a violência da ocupação na Amazônia. Trabalhadores "migrantes" são atraídos para os novos mercados de trabalho, como os polos agropecuários e minerais. De acordo com um levantamento realizado por Octávio lanni sobre o número de fazendas dedicadas à pecuária no Brasil, em especial o sul do Pará - município de Conceição do Araguaia -, que apresenta uma das maiores concentrações, constata-se que

em 1960, as fazendas que tinham como atividade principal a pecuária empregavam 144 trabalhadores permanentes e 209 temporários; em 1970, eram 183 permanentes e 218 temporários; já em 1972 este número salta para 857 trabalhadores permanentes e 7.011 temporários, sem incorporar trabalhadores não declarados (por exemplo, trabalhadores em regime de trabalho escravo $)^{11}$.

9 Ver PEREIRA. A luta pela terra no sule sudeste do Pará; há diversos registros de assassinatos, espancamentos, torturas, prisões que denunciam as ações conjuntas entre policiais e pistoleiros e, em alguns casos, militares (sul do Pará), ver os acervos da Prelazia de São Félix do Araguaia e da CPT (Comissão Pastoral da Terra), http://www.cptnacional.org.br/; conferir também o livro que faz um grande esforço de mapeamento dos mais diversos casos, em todas as regiões brasileiras: CARNEIRO, Ana; CIOCCARI, Marta. Retrato da repressão política no campo - Brasil (1962-1985). Camponeses torturados, mortos e desaparecidos. Brasília: MDA, 2010; consultar, ainda, GUIMARÃES NETO, Regina B. Vira mundo, vira mundo: trajetórias nômades. As cidades na Amazônia. Projeto História: Revista do Programa de Estudos Pós-Graduados em História e do Departamento de História da Pontifícia Universidade Católica de São Paulo, vol. 27, EDPUC, p. 49-69, 2003; e de PUHL, João Ivo. Tempo do Grilo: posseiros na gleba São Domingos (1979-1993). História da luta pela terra no Vale do Guaporé. Mato Grosso. Dissertação (Mestrado em História). Programa de Pós-Graduação em História-UFMT, 2003.

10 O Estado de São Paulo, 1975. FOWERAKER, Joe. A luta pela terra. A economia política da fronteira pioneira no Brasil de 1930 aos dias atuais. Tradução Maria Júlia Goldwasser. Rio de Janeiro: Zahar, 1982, p. 90.

11 Apud FOWERAKER. A luta pela terra, p. 89. 
Além disso, pequenos agricultores do Sul e trabalhadores sem terra do Nordeste, também estimulados pelas políticas governamentais a se dirigirem aos núcleos de "colonização" privada e "colonização" oficial (INCRA), não têm livre acesso à terra, como difunde a propaganda governamental. Ao contrário, ao migrarem, são surpreendidos por um território inóspito e desconhecido para eles, onde passam a vivenciar vários conflitos pela posse das áreas em disputa, desmandos de toda ordem, superexploração do trabalho, violência e assassinatos. ${ }^{12}$ Nas áreas dos projetos denominados de "colonização", ${ }^{13}$ os "colonos" mais descapitalizados - aqueles que chegam primeiro e desmatam grandes extensões de terra com mão de obra familiar - não apresentam condições econômicas de manter o lote/ sítio, comprado à prestação das empresas "colonizadoras". Estes trabalhadores do Sul, nomeados de "colonos" no Norte, transformam-se, em pouco tempo, em trabalhadores sem terra e vão engrossar as redes de deslocados da Amazônia.

\section{O tema trabalho}

As reflexões e análises sobre as experiências dos trabalhadores rurais da Amazônia, em diferentes espacialidades e temporalidades, pretendem somarse à contribuição dos estudos sobre o trabalho no mundo contemporâneo. Nas abordagens historiográficas, esse campo de investigação apresenta atualizações temáticas, abordagens teóricas inovadoras, além de problematizar a historicidade das categorias trabalho e trabalhador sob diversos ângulos. ${ }^{14}$

O tratamento que se dá à questão social do trabalho escravo no Brasil contemporâneo (designação da OIT) é emblemático como objeto de análise, por reivindicar novos usos das categorias históricas e chamar a atenção para a questão política que envolve a prática do historiador, como aponta Ângela de Castro Gomes:

Assim, a proposta [...] é compreender o fenômeno social designado como trabalho análogo a de escravo como um fato novo da história

12 Ver PEREIRA. A luta pela terra no sul e sudeste do Pará; ESTERCI, Neide. Escravos da desigualdade: estudo sobre o uso repressivo da força de trabalho hoje. Rio de Janeiro: CEDI, Koinonia, 1994; FIGUEIRA, Ricardo Rezende. Pisando fora da própria sombra; PETIT. Chão de promessas; ver ainda, acerca do tema da violência, as publicações anuais dos Cadernos de Conflitos no Campo, no site da Comissão Pastoral da Terra, disponível em: <http://www.cptnacional.org.br>.

13 Discuto em outros trabalhos a designação "colonização" e a renomeação que pequenos agricultores do Sul do Brasil recebem como "colonos". Ver "História, trabalho e política de colonização no Brasil contemporâneo: discursos e práticas. Amazônia”. In: MONTENEGRO, Antônio T.; GUIMARÃES NETO, Regina B.; ACIOLI, Vera (orgs.). História, cultura, trabalho: questões da contemporaneidade. Recife: Ed. da UFPE, 2011.

14 O aporte teórico que Ângela de Castro Gomes oferece ao analisar os usos da categoria "trabalho análogo a de escravo" ou "trabalho escravo contemporâneo" (designação da Organização Internacional do Trabalho) é muito significativo para a historiografia contemporânea; a autora investiga os regimes de historicidade a que se encontra submetido o conceito "trabalho escravo", na perspectiva do historiador alemão R. Koselleck ao analisar a historia social dos conceitos. GOMES, Ângela de Castro. Repressão e mudanças no trabalho análogo a de escravo no Brasil: tempo presente e usos do passado. Revista Brasileira de História. São Paulo, vol. 32, n 64, p. 167-84, 2012. Destaco, também, a contribuição inestimável dos historiadores brasileiros que se voltam para o estudo da Justiça do Trabalho e privilegiam a documentação produzida por esta instituição, em diversos estados. Para não me alongar nesta nota, restrinjo-me à indicação do recém-lançado livro organizado por GOMES, Ângela de Castro e SILVA, Fernando Teixeira da. A justiça do trabalho e sua história: os direitos dos trabalhadores no Brasil. Campinas: Editora da Unicamp, 2013. Não poderia deixar de lembrar a constituição do GT “Mundos do Trabalho" ligado a ANPUH, que vem contribuindo com a discussão sobre a temática, apresentando resultados na publicação da Revista Mundos do Trabalho. 
recente do Brasil que, se de um lado tem relações com práticas seculares de exploração do trabalhador, de outro possui singularidades próprias ao contexto das últimas quatro décadas de sua emergência e disseminação. (p. 12) [...] é fundamental observar que há atores e interesses envolvidos no processo de escolha de tal designação, que, como indiquei, embora estivesse no artigo 149 do Código Penal desde 1940, não causava grande espécie no meio acadêmico, nem mobilizava políticas públicas ou ações de organizações não governamentais nacionais e internacionais. [...] é possível afirmar que a questão não é tanto a existência do vocabulário tout court, mas a dos sentidos, a da abrangência, além da força política que ganha, o que, sem dúvida foi produto da intervenção de um conjunto de atores sociais após os anos de $1970 .{ }^{15}$

O escopo dessas análises não se restringe às condições sociais dos trabalhadores da Amazônia, mas amplia-se para contribuir com as pesquisas sobre o trabalho no mundo contemporâneo. Além disso, essa temática nos leva a discutir a interdisciplinaridade necessária que esses estudos exigem: um diálogo com a sociologia, a antropologia, a geografia e a filosofia, ${ }^{16}$ ao mesmo tempo em que o historiador se vê confrontado com sua própria prática historiográfica ao focalizar uma temporalidade que se coloca nos marcos da contemporaneidade ou do "tempo presente".

O tema do trabalho na Amazônia insere-se, portanto, na esfera de novos desafios metodológicos. De início, implica em questionar a volatilidade, a mudança e a diversidade dos conceitos e categorias com os quais designamos os trabalhadores em suas incontáveis facetas, atuando nas mais diversas atividades laborais, em um contexto histórico específico. Conceitos e categorias não têm sentido imóvel, universal, significações únicas. É importante que contemplem a complexidade histórica da experiência social em que se constituem, valorizando as particularidades das atividades realizadas, a fim de precisar os seus regimes de historicidade.

Nas práticas sociais dos trabalhadores que transitam pelas diversas áreas do território amazônico, no período histórico focalizado, encontra-se a expressão de uma força de trabalho alocada nas mais diversas atividades, seja assalariado, não assalariado, em regime temporário, ou outras formas de relações de trabalho. Muitos deles, facilmente flagrados sem contrato de trabalho e em situação análoga a de escravo. A imobilização do trabalhador na propriedade rural ou área de trabalho deixa de ser a única condição que distingue o "trabalho análogo a de escravo", questão que é alvo de inúmeras análises e controvérsias, além da discussão nuclear da própria denominação. Na configuração da experiência do trabalhador em situação de "trabalho escravo" são avaliados vários aspectos que caracterizam as condições e práticas de trabalho, como a moradia, a alimentação, hora útil de trabalho empregado, trabalho não pago e endividamento, etc., que podem caracterizar o que se denomina de "trabalho degradante": dignidade negada em absoluto. ${ }^{17}$

15 GOMES, Ângela de Castro. Trabalho análogo a de escravo: construindo um problema. História Oral: Revista da Associação Brasileira de História Oral. Rio de Janeiro: Associação Brasileira de História Oral, vol. 11, $\mathrm{n}^{\circ} 1-2$, p. 21, 2008.

16 Consultar, especialmente, Conflitos no campo, Brasil 2009. Goiânia: CPT, 2010 (e também vários artigos publicados em anos anteriores): http://www.cptnacional.org.br/. Além desta indicação, ver autores que tratam da questão da exploração do trabalho, que vêm sendo citados neste artigo.

17 Ver especialmente, entre outras contribuições, os textos de: GOMES, Ângela de Castro. Repressão e 
Posições atualizadas sobre a questão "trabalho" são contrárias ao uso de categorias que desqualificam e homogeneízam a presença do trabalhador. Muitas vezes nomeados de peões, ou mesmo 'pés inchados', os trabalhadores são constantemente alvos de denominações que pouco traduzem a diversidade social e cultural desse mundo. O historiador Leandro $G$. Cerutti abre um rico leque de discussão ao abordar a condição de vida e trabalho de homens designados como "peão de trecho", "peão-rodado”, ou, apenas, "peão”, "trecheiro”, entre tantos outros termos. Para isso, o autor montou um glossário, apoiando-se na diversidade das denominações, sobretudo valorizando as autodenominações que ouviu dos próprios trabalhadores quando realizava a pesquisa para a sua dissertação, ${ }^{18}$ que trata do período após a década de 1970.

A mão de obra, também nomeada como braçal, chega mesmo a ser identificada com "andarilhos", "pés-inchados", 19 sobretudo nas tarefas que executam nos desmatamentos, construção de cercas, limpeza das áreas para lavouras, como o trabalho dos "destocadores" (antes da passagem dos tratores) etc. Há uma pluralidade de usos dessa força de trabalho, considerada descartável, numa realidade social em que as atividades laborais subdividem-se e transformamse constantemente em inúmeras outras, sobretudo considerando as grandes áreas relacionadas aos polos de investimentos agropecuários, de mineração e colonização após a década de 1970.

Assim sendo, para a compreensão da complexidade social do trabalho na Amazônia, torna-se crucial uma reflexão que desconstrua representações e conceitos instituintes de evidências, que produza deslocamentos analíticos. É preciso problematizar os discursos, relatos e textos relacionados ao mundo do trabalho, em que, e apenas neles, conceitos e categorias adquirem significado, ou seja, quando expressam a condição situacional em que se encontram os trabalhadores. Portanto, é preciso entender que a linguagem e os discursos são produtores de representações e práticas, comprometidas com a lógica discursiva da identidade e, também, com as exclusões reprodutoras das relações de exploração. Por isso, ao situar as relações de trabalho no quadro das atividades agrícolas, pecuária e/ou agroindustrial, mineral, mineral-metalúrgica e vegetal, na Amazônia, é imprescindível especificar, particularmente, sobre quais práticas incide a análise a ser realizada e quais imagens e signos veiculam.

Além disso, necessário se faz investigar, no período do regime civil-militar no Brasil, após 1964, as alianças específicas entre capital e Estado - compreendidas

mudanças no trabalho análogo a de escravo no Brasil: tempo presente e usos do passado. Revista Brasileira de História, op. cit; FIGUEIRA. Pisando for a da própria sombra; GUIMARÃES NETO, Regina B. História, política e testemunho: violência e trabalho na Amazônia Brasileira. A narrativa oral da presidenta do Sindicato dos Trabalhadores Rurais de Confresa - Mato Grosso, Aparecida Barbosa da Silva, op. cit. JOANONI NETO, Vitale. Da histórica dominação sobre vidas prescindíveis. As muitas faces da violência sobre trabalhadores migrantes no nordeste de Mato Grosso do final do século XX. In: HARRES, Marluza; JOANONI NETO, Vitale (org.). História, terra e trabalho. Ensaios teóricos e resultados de pesquisas, op. cit.; PLASSAT, Xavier. Erradicação do trabalho escravo? Ficou para outra vez. In: Conflitos no Campo, Brasil-2005. Goiânia: Comissão Pastoral da Terra, 2006, p. 146-151. PLASSAT, Xavier. Trabalho escravo: 25 anos de denúncia e fiscalização. In: Conflitos no campo 2009/CPT; Coordenação: Antonio Canuto, Cássia Regina da Silva Luz, Isolete Wichinieski. São Paulo: Expressão Popular, 2010, p. 90-100; ORGANIZAÇÃO INTERNACIONAL DO TRABALHO, SAKAMOTO, Leonardo (coord.) Trabalho escravo no Brasil do Século XXI. Brasília; OIT, 2006. VIEIRA, Maria Antonieta da Costa; ESTERCI, Neide. Trabalho escravo no Brasil: os números, as lutas e as perspectivas em 2003. In: Comissão Pastoral da Terra, Conflitos no Campo, Brasil-2003, CPT, Goiânia, 2004.

18 Deslocamento social e trabalho temporário: práticas e relatos de trabalhadores em Primavera do Leste, Mato Grosso. Dissertação (Mestrado em História). Programa de Pós-Graduação em História-UFMT, 2004.

19 Idem. Ver também GUIMARÃES NETO, Regina B. Vira mundo, vira mundo: trajetórias nômades. As cidades na Amazônia, op. cit. 
pelas práticas de governo e seus diversos órgãos. Nessas articulações é que se estabelecem as condições de possibilidade da existência de práticas de exploração do trabalho fora do ordenamento jurídico, o qual deveria assegurar direitos aos trabalhadores. É importante colocar no centro da pesquisa histórica as configurações políticas que tornam possíveis as relações de exploração social nas suas especificidades.

\section{Historiografia e memória de luta dos trabalhadores}

A historiografia vem, cada vez mais, valorizando os testemunhos dos atores sociais, escritos ou orais, diretamente envolvidos nos conflitos sociais e em acontecimentos traumáticos. O direito à memória daqueles que têm pouco ou quase nenhum lugar na história, homens e mulheres desconhecidos, anônimos, alvo da extrema violência física e simbólica por parte dos segmentos sociais que detêm o poder "da lei e da arma", reivindica a importância da transmissão dos acontecimentos constitutivos de suas vidas, que, de outro modo, estariam fadados a habitar uma zona do esquecimento. Tais registros apresentam uma dimensão individual e social importante, enquanto produção do conhecimento, e que se conectam a milhares de histórias dos trabalhadores rurais no Brasil.

Discute-se, problematiza-se amplamente, no momento histórico atual, o excesso de memória, ${ }^{20}$ "os usos políticos do passado", sobretudo ligados às ditaduras militares na América Latina. E, no Brasil, com os levantamentos anunciados pelas Comissões da Verdade (criadas pelo Estado) e outras contribuições, uma série de relatos vem à tona, trazendo narrativas testemunhais que lançam novas luzes às práticas políticas dos militares e civis no período da ditadura, no campo e na cidade. ${ }^{21}$

A história também enfrenta outros desafios. Marieta Moraes de Ferreira discute uma temática crucial para os historiadores hoje: as demandas sociais da história. ${ }^{22}$ Mesmo diante da indeterminação de tais demandas, a autora avalia os desafios que as novas solicitações exigem, problematizando a abordagem e o tratamento, sobretudo do tema da memória (entre o dever de memória e os abusos da memória) e do estatuto dos testemunhos individuais e coletivos, alertando contra os vícios ou hábitos incorporados nas análises que incorrem na produção da vitimização social.

Entretanto, há certos materiais de memória que não mereceram a atenção devida da historiografia. No Brasil, desde o período do regime civil-militar - e não apenas nele - milhares de trabalhadores rurais foram assassinados, presos, torturados. Famílias e mais famílias foram expulsas de suas terras; crianças cresceram com o luto da morte dos pais. Tudo isso é amplamente documentado

20 Ver as considerações da argentina Beatriz Sarlo, para quem há de se ter o cuidado de discernir ou problematizar as relações entre testemunho e compreensão histórica da experiência vivida. Tempo passado: cultura da memória e guinada subjetiva. Tradução Rosa Freire d’Aguiar. São Paulo: Cia da Letras; Belo Horizonte: UFMG, 2007.

21 Além dos levantamentos que estão sendo realizados pelas Comissões da Verdade, ressalto a contribuição dos livros: MONTENEGRO, Antonio Torres; Maria Paula N. Araújo; Carla Rodeghero. Marcas da memória: história oral da anistia no Brasil. Recife: Ed. Universitária da UFPE, 2012; e para o campo, CARNEIRO, Ana; CIOCCARI, Marta. Retrato da repressão política no campo - Brasil (1962-1985). Camponeses torturados, mortos e desaparecidos, op. cit.

22 FERREIRA, Marieta de Moraes. Demandas sociais e história do tempo presente. In: VARELLA, Flávia et al (orgs.). Tempo presente \& usos do passado. Rio de Janeiro: Ed. FGV, 2012, p. 101-124. 
por diversas fontes - especialmente pela Comissão Pastoral da Terra - e noticiadas, muitas vezes, pela própria imprensa. Há que se destacar as matérias feitas pelo Jornal do Brasil, na década de 1970, noticiando flagrantes de trabalho escravo, pela Polícia Federal, nas fazendas da Amazônia, até mesmo denunciando a existência de grandes cemitérios clandestinos. ${ }^{23}$

\section{Memória da violência: trabalhadores rurais e conflitos sociais no Araguaia}

Na perspectiva adotada neste artigo, o passado - segundo o historiador François Dosse ${ }^{24}$ - "é ainda carregado por uma palavra que pode ser exigida a testemunhar [...]" Nesses termos, penso nos registros que hoje se encontram arquivados na Prelazia de São Félix do Araguaia, ${ }^{25}$ em Mato Grosso, organizados no período de atuação do bispo Pedro Casaldáliga, ${ }^{26}$ até os dias de hoje. Lá estão palavras que revelam múltiplas histórias, carregadas de infelicidade que, como diz Foucault, "não podem ser um resto mudo da política".

$O$ arquivo é um testemunho imprescindível para a memória das violências ocorridas contra trabalhadores, posseiros, índios, moradores dos pequenos povoados do Araguaia e religiosos. ${ }^{27}$ Os historiadores encontram neste material uma base importante para o trabalho com a memória, a fim de estabelecer relações fulcrais entre o testemunho (relato do que foi vivido pela testemunha) e a explicação histórica, considerando especialmente o que Maria de Lourdes Janotti assinala acerca do estatuto "intrinsecamente político" do testemunho. ${ }^{28}$ Desse modo, problemas teóricos e metodológicos desafiam os historiadores ao lidarem com o tecido complexo da memória, pelos usos dos testemunhos escritos ou orais. Institui-se "um processo epistemológico que parte da memória declarada, passa pelo arquivo e pelos documentos e termina na prova documental". ${ }^{29}$ Mais que isso, atravessando esse percurso, no campo da historiografia, a memóriadeclarada, produzida como documento, torna-se narrativa histórica.

Nessa senda, os documentos não "dizem" a história, mas é no âmbito da operação historiográfica que inscrevem significados, fundamentais para a compreensão do momento histórico que expressam e contam. Por isso, torna-se

23 A antropóloga Neide Esterci utilizou amplamente em suas pesquisas vários levantamentos realizados com as matérias veiculadas pelo Jornal do Brasil, como as denúncias de trabalho análogo a de escravo. Este periódico publicava as práticas ilegais cometidas por proprietários de terras, além de diversos flagrantes e apreensões realizadas pela Polícia Federal. Os textos de Esterci se encontram indicados em várias notas deste artigo.

24 DOSSE, François. Renascimento do acontecimento: um desafio para o historiador: entre Esfinge e Fênix. Tradução Constancia Morel. São Paulo: UNESP, 2013, p. 307.

25 A Prelazia de São Félix do Araguaia abrange uma área de 150.000 km² de extensão, com 15 municípios, localizados na parte nordeste do estado de Mato Grosso, até os limites, ao norte, com o estado do Pará e, a leste, com os estados de Tocantins e Goiás.

26 Pedro Casaldáliga foi bispo da Prelazia de São Félix, no período de 1971 a 2005. Adepto da teologia da libertação ajudou a fundar a Comissão Pastoral da Terra (CPT), durante o Encontro de Pastoral da Amazônia, convocado pela Conferência Nacional dos Bispos do Brasil (CNBB), realizado na cidade de Goiânia (GO), em junho de 1975.

27 O arquivo da Prelazia constituiu-se aos poucos e contou com a imprescindível organização da Irma Irene Fraceschini, que a ele dedicou mais de 30 anos de sua vida.

28 Ver o importante artigo desta autora: A incorporação do testemunho oral na escrita historiográfica: empecilhos e debates. História Oral: Revista da Associação Brasileira de História Oral, vol. 13. Rio de Janeiro: Associação Brasileira de História Oral, 2010.

29 RICOEUR, Paul. A memória, a história, o esquecimento. Tradução Alain François [et al.]. Campinas: Editora da Unicamp, 2007, p. 170. 
tão importante que pesquisadores tenham acesso aos acontecimentos descritos e amplamente denunciados no Brasil e em outras partes do mundo pelo bispo e outros padres e auxiliares pastorais da Prelazia. Cartas, relatórios, ofícios, livros, jornais, revistas e inúmeras denúncias de trabalhadores que fogem das fazendas, algumas delas escritas de próprio punho - bilhetes e declarações -, certificadas com assinaturas ou digitais, apresentam uma contribuição inestimável à história do trabalho e do conflito social na Amazônia. Além disso, lá se encontram documentados toda sorte de maus tratos, torturas e assassinatos, além das verdadeiras "caçadas" aos fugitivos-peões praticados pelos gerentes, empreiteiros e pistoleiros contratados das fazendas, e com a participação da polícia militar. Inúmeras famílias foram destruídas; mulheres e homens assassinados na frente dos filhos, e homens que continuaram a morrer anos depois em decorrência das violências sofridas e das prisões arbitrárias. Esta multiplicidade de registros foi guardada no acervo da Prelazia e faz do seu arquivo um lugar social e, no caso da Prelazia, não apenas um lugar religioso, mas político.

Os testemunhos, segundo Ricoeur, estão na origem do discurso histórico e têm empregos múltiplos, seja o uso jurídico seja o uso histórico. ${ }^{30}$ Pode-se inferir que havia por parte da Prelazia grande interesse no uso das declarações e toda sorte de registros nessas duas dimensões: tanto como prova da superexploração do trabalho, assinalando o emprego de trabalho escravo pelas agropecuárias da região e as diversas violências a posseiros, índios e demais moradores, quanto para a salvaguarda de uma memória dos conflitos sociais e, especialmente, uma memória das atividades pastorais da Prelazia, o seu trabalho cristão. É significativo assinalar que este aspecto, os registros dessas atividades e o alcance político delas, assim como o poder de penetração popular fortaleciam, nas disputas internas da Igreja Católica, os padres e freiras que se comprometiam com a linha da teologia da libertação. Esta orientação religiosa e política tornava ativa a presença da Igreja nos locais de agudos conflitos sociais. ${ }^{31}$

Na Carta Pastoral, "Uma igreja da Amazônia em conflito com o latifúndio e a marginalização social”, publicada em 10 de outubro de 1971, dias antes de receber a sua ordenação episcopal, Pedro Casaldáliga anuncia: ${ }^{2}$

O ‘momento publicitário’ de projetos e realizações que a Amazônia está vivendo, e a opção de prioridade que a própria Igreja do Brasil fez por ela, através da CNBB, justificam também com nova razão esta minha declaração pública.

E esta "declaração", que toma a forma de uma ampla denuncia pública, questiona os poderes públicos quanto à política adotada para a "integração e desenvolvimento da Amazônia", que fere os direitos primordiais do homem em um momento de grande repressão política no Brasil com o governo Médici:

30 RICOEUR, Paul. Idem. Ver também: GINZBURG, Carlo. Le juge et I'historien. Paris: Verdier, 1997; do mesmo autor. Provas e possibilidades. O retorno de Martin Guerre. In: O fio e os rastros. Verdadeiro, falso, fictício. São Paulo: Cia das Letras, 2007, p. 311-335. Ver ainda, MONTENEGRO, Antônio Torres. Ação trabalhista, repressão policial e assassinato em tempos de regime militar. Rio de Janeiro: Topoi, vol. 12, $\mathrm{n}^{\circ} \mathrm{22}$, jan.-jun., 2011, p. 228-49.

31 MARTINS, José de Souza. A política do Brasil: lúmpen e místico, especialmente o capítulo: "Camponeses e índios na renovação da orientação pastoral da Igreja".

32 Pedro Casaldáliga publicou sua carta pastoral em 10 de outubro e no dia 23, desse mesmo mês, seria ordenado bispo da Prelazia de São Felix do Araguaia, Mato Grosso. Entretanto, o Papa Paulo VI já o havia nomeado bispo prelado de São Félix do Araguaia no dia 27 de agosto de 1971. 


\begin{abstract}
Mais uma vez, com maior premência, publicamente, apelamos às supremas Autoridades Federais - Presidência da República, Ministérios da Justiça, do Interior, da Agricultura, do Trabalho, INCRA, FUNAI... [...] para que subordinem os interesses dos particulares ao bem comum, a "política da pata do boi" à política do homem, os grandes empreendimentos - sempre mais publicitários - das estradas, ocupação da Amazônia, a Mesopotâmia do gado", a mal chamada "integração nacional do índio", às necessidades concretas e aos direitos primordiais, anteriores, do homem nordestino, do retirante sem futuro, do homem da Amazônia, do índio, do posseiro, do peão [...]
\end{abstract}

Nesta carta, o bispo denuncia publicamente a violência contra os indígenas e os posseiros que se encontram na "região do Araguaia" e os trabalhadores - designados peões - que ali chegavam continuamente levados pelos empreiteiros - denominados gatos - contratados pelas agropecuárias. Tal situação ocorre em várias áreas da Amazônia, contudo há uma incidência maior na parte nordeste de Mato Grosso e no sul do Pará, em razão da concessão dos incentivos fiscais e outros aportes financeiros da SUDAM (Superintendência do Desenvolvimento da Amazônia). É bom lembrar, também, que uma agropecuária como a da Volkswagen (sul do Pará) aparece como dona de mais de 100.000 ha; a Suiá-Missú (nordeste de Mato Grosso, município de São Félix do Araguaia), com 695.843 ha; a Codeara (nordeste de Mato Grosso), 196.497,19 ha. A lista é grande, conforme aponta Pedro Casaldáliga na Carta Pastoral "Uma igreja da Amazônia em conflito com o latifúndio e a marginalização social".

$\mathrm{Na}$ trilha de suas declarações, protesta ainda contra a política que privilegia e faz da pecuária a opção econômica para o que chamam de ocupação da Amazônia:

A publicidade faz dos fazendeiros os bandeirantes da região. O Sr. Ministro da Agricultura, Cirne Lima, porém, falando aos técnicos reunidos pela " Semana do Veterinário", em Brasília, diz que "o boi deverá ser o grande bandeirante da década [...]".33

A partir da publicação da Carta e de várias declarações públicas, o bispo foi alvo de diversas ameaças de morte. A mais grave, em 12 de outubro de 1976, ocorreu no povoado de Ribeirão Bonito (Mato Grosso). Ao ser informado que duas mulheres estavam sendo torturadas na delegacia local, dirigiu-se até lá acompanhado do padre jesuíta João Bosco Penido Burnier. Após forte discussão com os policiais, o padre Burnier ameaçou denunciá-los às autoridades, sendo então agredido e, em seguida, alvejado com um tiro na nuca.

A Carta com seu poder de denúncia, em pleno Al-5, quando a imprensa estava sob censura, opera como um desafio da Igreja Católica a todo o discurso desenvolvimentista e ufanista do governo Médici, reafirmando a postura cristã contra o lucro e as grandes empresas, denunciando o subdesenvolvimento e declarando sua "opção pelos pobres". ${ }^{34}$ José de Souza Martins discute a ampla reorientação do trabalho pastoral, desde 1968, que muda a proposta da Igreja Católica ao se deparar com o "capital moderno - segundo suas palavras - que se apresenta como proprietário de terra e o próprio Estado como seu mentor e

33 O Estado de São Paulo, 15 de setembro de 1971.

34 É a Igreja Católica após Medellín. Ver SCALOPP, Marluce. Práticas mediáticas e cidadania no Araguaia: O Jornal Alvorada. Cuiabá: KCM Editora, 2012. 
financiador". ${ }^{35}$ As denúncias da Igreja se avolumam ano a ano, chegando a CPT a registrar que, em 1981, mais de vinte milhões de hectares de terra haviam sido obtidos por meios ilegais e violentos na Amazônia. E pelos registros do Movimento dos Trabalhadores Rurais sem Terra, dos assassinatos no campo entre 1964-1986, mais de mil camponeses foram assassinados entre 1970 e 1985, metade deles na Amazônia. ${ }^{36}$

Diante de um quadro violento de expansão das grandes empresas privadas e dos conflitos sociais desencadeados, além da utilização de trabalho escravo, um escândalo social, apontando um número de aproximadamente 90 mil trabalhadores escravizados a partir de 1970, a Igreja assume uma nova orientação política e seus bispos lançam documentos que denunciam a desigualdade e a violência, agora, em relação ao conflito de classe. ${ }^{37}$

Pedro Casaldáliga pertence a essa nova configuração e torna-se um dos mais aguerridos sacerdotes empenhados na luta social. Para fazer valer o poder simbólico de seu relato de enfrentamento, com maior impacto político, aguarda ser sagrado bispo, como declara: "só lancei a Carta Pastoral no dia que fui sagrado bispo. Se fosse um simples padre, leigo ou leiga, me cortavam o pescoço". ${ }^{38}$ Contudo, nesse momento, o gesto corajoso e arrojado do bispo conta com o apoio imprescindível da CNBB, que não apenas promove o uso dos meios de comunicação de massa, mas organiza uma rede de correspondentes em várias cidades brasileiras articulada com diversos outros meios de comunicação e, mesmo, com entidades e instituições internacionais. ${ }^{39}$

Abrem-se os caminhos, dessa forma, para os desafios e denúncias. O discurso do bispo Casaldáliga chama a atenção para o que se encontra na base da aliança entre o Estado e o capital nacional e internacional ao afirmar que, na verdade, o que se assiste na Amazônia, "a terra sem homens para homens sem terra", ${ }^{\circ}$ como símbolo da "riqueza inesgotável” do Brasil, é a miséria da exploração social, sobretudo pelas grandes empresas agropecuárias. A linguagem utilizada pelo bispo faz com que a concepção de desenvolvimento perca a sua neutralidade e compromete o Estado com a violência operada pelo grande capital e os chamados "latifundiários".

Essa crítica aos fundamentos dos investimentos capitalistas na Amazônia, vistos como produtores de profunda desigualdade social, revela como os argumentos cristãos tornam-se valiosos para os enfrentamentos políticos. Desse modo, acabam por conformar o discurso do bispo como um pronunciamento político. Ao mesmo tempo em que se constitui em uma palavra-testemunho, a dimensão política de seu discurso alcança o espaço público e afirma ainda mais seu compromisso com os pobres e explorados, especialmente quando ascende na hierarquia eclesiástica. Assim, o discurso do bispo Pedro Casaldáliga dá publicidade aos eventos - matéria política no espaço público - e transforma-os em acontecimentos históricos.

35 MARTINS, José de Souza. A política do Brasil: lúmpen e místico, op. cit.; do mesmo autor, A militarização da questão agrária no Brasil, op. cit., p. 169 (ver especialmente as páginas 163-175).

36 Assassinatos no campo: crime e impunidade (1964-1986) 2. ed., São Paulo: Global, 1987.

37 José de Souza Martins ainda vai mais longe. Baseando-se em uma pesquisa das jornalistas inglesas Sue Branford e Oriel Glock, sugere que entre 250 mil e 400 mil trabalhadores foram submetidos a cativeiro na região amazônica. Ver A política do Brasil: lúmpen e místico, op. cit., p. 165.

38 Apud SCALOPP, Marluce. Idem.

39 Ver a importante análise acerca do poder de comunicação da CNBB no livro de SCALOPP, Marluce. Práticas mediáticas e cidadania no Araguaia, op. cit.

40 Discurso do presidente Médici, na Reunião Extraordinária da SUDAM (Manaus, 8 de outubro de 1970), já citado à página 4. 
É a primeira vez que um discurso, com capacidade de ampla repercussão nacional e internacional, denuncia o trabalho dito "escravo" no Brasil; ${ }^{41}$ as condições subumanas a que eram submetidos os trabalhadores nas fazendas, morrendo aos magotes, sem nenhuma assistência à saúde, em áreas infestadas pelo mosquito da malária, além das práticas de endividamento que retinham os trabalhadores nas áreas dos desmatamentos e nas fazendas - a prática do aprisionamento por dívida - sob o poder das armas dos jagunços, empreiteiros (gatos), gerentes, "fiscais" e mesmo as polícias.

No entanto, fazendeiros, gerentes, empresários e policiais não foram incriminados e ficaram impunes sob os discursos do progresso do governo federal, veiculando propagandas que tinham como slogan: integração, desenvolvimento e segurança nacional. Esta é uma memória da ditadura militar na história do Brasil ainda pouco contabilizada.

\section{As declarações dos trabalhadores: o valor dos testemunhos ${ }^{42}$}

As declarações e denúncias, testemunhos da violência, são assinados ou atestados pelas digitais dos trabalhadores, que eram compulsoriamente obrigados ou "condenados" a prestar serviços a grandes empresas agropecuárias no Araguaia, ${ }^{43}$ como a Cia. de Desenvolvimento do Araguaia - Codeara, Bordon S/A Agropecuária da Amazônia, Fazenda Suia-Missú, Agropecuária Nova Amazônia S/A - Frenova, Reunidas, Brasil Novo, Tamakavy, entre muitas outras. ${ }^{44}$

Entre várias declarações, a do trabalhador chamado Elias Lima de Souza que aparece datilografada, mas assinada por ele com sua digital e a de sua esposa, Joaquina Monteiro dos Santos, que escreve de próprio punho, é muito valiosa por vários aspectos, especialmente pela denúncia de trabalho não pago a ele, a esposa (o trabalho feminino num ambiente com predominância masculina) e aos trabalhadores companheiros de serviço; ameaças constantes de violência física e psicológica, tortura e espancamento na área de trabalho; além do testemunho de fugas de trabalhadores da área da fazenda. Reproduzo a declaração tal qual consta no registro, arquivado na Prelazia:

\section{DECLARAÇÃO}

Eu abaixo-assinado, Elias Lima de Souza, de 51 anos de idade, natural de Grajaú, MA, casado, residente em São Félix, MT, declaro que:

- trabalhei em derrubada, na fazenda "BELA MANHÃ", do dia 22 de março pp. até o dia 29 de maio; às ordens do empreiteiro Joaquim (Fogolhô). Recebi 100 (cem) cruzeiros, do "gato", na saída para o serviço e nunca mais recebi outro pagamento nenhum. Constantemente o empreiteiro Joaquim nos ameaçava com furar e matar e se gabava de ter costume de fazer isso, do Pará até aqui; com os Caiado, no Goiás, etc. etc.

41 Até este momento, usavam-se as expressões "trabalho forçado", "escravidão branca" e outras designações. Ver, especialmente, ESTERCI, Neide. Escravos da Desigualdade: estudo sobre o uso repressivo da força de trabalho hoje, op. cit.;

42 Os relatos, ofícios e declarações que se seguem se encontram no arquivo da Prelazia de São Félix do Araguaia, digitalizados. www.prelaziasaofelixdoaraguaia.org.br.

43 Idem. Ver também: ESTERCI, Neide. Escravos da desigualdade: estudo sobre o uso repressivo da força de trabalho hoje, op. cit.

44 Uma igreja da Amazônia em conflito com o latifúndio e a marginalização social, op. cit.; ESTERCl, Neide. Conflito no Araguaia. Peões e posseiros contra a grande empresa. Petrópolis: Vozes, 1987. 
- minha esposa, Joaquina Monteiro dos Santos, de 40 anos de idade, natural de Grajaú, MA, trabalhou durante o mesmo tempo, de cozinheira, na mesma fazenda, e nunca tirou pagamento nenhum.

- de duzentos e poucos homens que trabalhavam na fazenda durante o meu tempo de serviço, quando eu saí ficavam uns 30: o resto saiu, fugido ou na marra; muitos deles sem receber pagamento.

- vários homens foram ameaçados, alguns foram espancados, o chamado "Ciarence" foi amarrado numa árvore...

A fazenda "BELA MANHÃ" está situada entre a estrada BR-158 e o rio Suias..o [ilegível... Certamente, refere-se ao rio Suiá-Missu ou Suiá Miçu], município de Barra dos Garças, MT.

E para que conste como sendo verdade, assinamos minha esposa e eu, aqui, em São Félix, a 6 de junho de 1972.

A declaração é seguida das assinaturas dos dois, a de Elias com a digital e de Joaquina, assinatura de próprio punho.

Esta denúncia repete várias acusações feitas pelos trabalhadores em outras declarações e testemunhos escritos, tais como os pagamentos não realizados, o trabalho degradante e compulsório, a violência cotidiana, para não citar as doenças, pois estas constituem outro capítulo que se aproxima de um verdadeiro genocídio nas diversas áreas da Amazônia, especialmente a malária e diarreias, morrendo, muitos deles, em condições subumanas. Na verdade, configuram-se, diante deste quadro, desde finais da década de 1960, as condições históricas que se estabelecem ou se tornam dominantes para o que será definido e considerado hoje trabalho degradante e trabalho análogo ao de escravo. ${ }^{45}$

No contexto político das décadas de 1970 e 1980, as impunidades relativas às violências, como o aprisionamento de homens e mulheres nas áreas de trabalho e o não pagamento aos trabalhadores, concorreram para instituir o que veio a ser nomeado "escravidão por dívida", considerado "trabalho escravo". ${ }^{46}$ Sob tarefas exaustivas, tratados como animais, quando iam cobrar o serviço prestado, viam que estava tudo incluído no item "despesas", não restando nada a receber, pelo contrário, havia de "saldo" dívidas e mais dívidas, devendo, pois, quitá-las para poderem sair. E não apenas isso. Se, diante de tal situação, mencionavam o desejo de abandonar o trabalho, eram ameaçados de morte pelos gerentes, empreiteiros e pistoleiros contratados, quando não assassinados ou "caçados".

E pedi mais uma vez o meu pagamento. O Aldenor me xingou de todo nome. Repliquei dizendo que era homem como ele e que me tratasse como gente. Aldenor tirou o facão e partiu para cima de mim. Conseguiu ferir-me a coxa direita. Com muito esforço, tirei-Ihe o facão. Sem o facão, tirou o revólver e atirou em mim. Por trás o Geraldo também atirava. Fui baleado no ombro esquerdo. Fugi e disse que ia fazer denúncia. Fui parar numa pensão que está perto e lá me atenderam. (José Geraldo,

45 Consultar o artigo 149 do Código Penal brasileiro, que penaliza como crime: "Reduzir alguém à condição análoga a de escravo: Pena - reclusão de 2 (dois) anos a 8 (oito) anos." Em 11 de dezembro de 2003, a Lei n 10.803 altera a redação do artigo 149 e amplia o leque do que consideram as "Formas Contemporâneas de Escravidão", incluindo jornadas exaustivas, condições degradantes de trabalho, além da imobilização dos trabalhadores, em razão de dívida contraída, com o empregador ou preposto. GOMES, Ângela de Castro. Repressão e mudanças no trabalho análogo a de escravo no Brasil: tempo presente e usos do passado. Revista Brasileira de História, op. cit.; e da mesma autora: Trabalho análogo a de escravo: construindo um problema. História Oral: Revista da Associação Brasileira de História Oral, op. cit. Ver também GUIMARÃES NETO, Regina B. História, política e testemunho: violência e trabalho na Amazônia Brasileira. A narrativa oral da presidenta do Sindicato dos Trabalhadores Rurais de Confresa - Mato Grosso. História Oral: Revista da Associação Brasileira de História Oral.

46 ESTERCI. Conflito no Araguaia.; FIGUEIRA. Pisando Fora da Própria Sombra; consultar também outros textos de autores já citados neste artigo, que discutem o tema relacionado a "trabalho escravo". 
nascido em Jacobina, Bahia: declaro que fui contratado para trabalhar na Fazenda “Tamakavy” por Luís chamado Lagoa...)

Há inúmeros registros no arquivo da Prelazia das ações de empregados nas fazendas, denominados de "fiscais", acompanhados pelos policiais, em busca dos "fugitivos". Muitas vezes os próprios padres e agentes pastorais os escondiam:

É, naquele tempo, era um tempo que o pessoal trazia os peões [...] Cada ano trazia de um canto. Porque, no ano seguinte, já a notícia chegava no lugar de origem e não vinham do mesmo lugar. Mas, por exemplo, em 1972, vieram do Piauí, de Floriano. Eu mesmo ajudei uns 70 a fugir. Eles chegavam lá em casa e eu os escondia lá no morro e, de noite, atravessavam o Araguaia e iam embora. ${ }^{47}$

Também são relatados nas declarações e denúncias os mais diversos tipos de eventos como torturas, espancamentos, privações de toda sorte, como falta de comida e alimento estragado, ausência de remédios e abandono à morte. Para tanto, nos casos de violência física, as empresas contavam diretamente com o apoio da Polícia Militar, numa intricada relação de força e violência entre proprietários de terra, polícia e pistoleiros, além da concordância e apoio da justiça.

Os trabalhadores para chegarem a prestar seus depoimentos passaram por situações que os colocaram entre a vida e a morte, escapando em situações-limite, quando iam ser assassinados; ademais é preciso analisar a linguagem utilizada para testemunhar, ela tem um estatuto declarativo. É descritiva, relata o acontecido no tempo e no espaço; nomeia os envolvidos; indica os lugares dos eventos; assina os nomes próprios, muitas vezes com a letra pouco legível e tremida; apresenta, muitas vezes, o local de nascimento, de moradia, e o estado civil, moços ou velhos, com ou sem filhos.

Os registros destas declarações são conduzidos pela Prelazia, a fim de produzi-los como documentos-denúncia (por isso o cuidado com as informações passadas). Declarações, denúncias, depoimentos, testemunhos escritos e orais ampliam este leque. Contudo, descobre-se também a existência de vários bilhetes que os próprios trabalhadores usaram para poder escapar das fazendas, forjando "autorizações" dos gerentes a fim de burlar a vigilância nos locais de saída das fazendas e/ou áreas de desmatamentos.

Outros documentos são ainda relatórios da própria Prelazia noticiando diversos casos e ofícios à Polícia Federal, pedindo intervenção (não se poderia recorrer à polícia local, pois a mesma atuava auxiliando fazendeiros e empreiteiros). Reproduzo um dos ofícios, paradigmáticos dos procedimentos que a Prelazia realizava e encaminhava à Polícia Federal:

47 Este fragmento é parte de uma entrevista feita a Antônio Canuto (da Comissão Pastoral da Terra - CPT), pelas Professoras Maria Aparecida Martins Souza (UNEMAT) e Marluce de Oliveira Machado Scaloppe (UFMT), em Goiânia, 2009, transcrita por Maria Izabel Cruz Bitar, em 28 de janeiro de 2010. Projeto: Trabalho análogo a escravo: história, memória e tempo presente. Centro de Pesquisa e Documentação de História Contemporânea do Brasil (CPDOC), Rio de Janeiro. 
PRELAZIA DE SÃO FÉLIX

MATO GROSSO - BRASIL

Exmo. Sr.

Dr. Nilo Canepa

DD. Diretor do Departamento de Polícia Federal

BRASÍLIA - DF

Exmo. Sr.

Sou o vigário substituto da Paróquia de Santa Terezinha, no povoado de Santa Terezinha, MT, e através desta dirijo-me a V. Exa . e ao órgão que $V$. Exa. dirige para expor assunto que, no meu modo de pensar, é de extrema gravidade. Não sei se é o órgão competente a quem deveria apesar, mas como já ouve outras intervenções do mesmo neste sentido, por isso dirijo-me a ele.

O motivo que me leva a endereçar-lhe esta carta-relatório é o seguinte: Quase diariamente sou procurado na Casa Paroquial por um bom número de peões, trabalhadores braçais da Cia. de Desenvolvimento do Araguaia - CODEARA, que vem pedir proteção, ajuda e cobertura para poderem se afastar da situação infra-humana na qual caíram, enganados. V. Exa. deve ter conhecimento de um grande processo aberto contra a citada $\mathrm{Cia}$. Por exploração de trabalho escravo em 1970. A própria Polícia Federal teve intervenção decisiva no caso retirando na ocasião, uns 500 peões que se sentiam escravizados. Pois bem, a atuação da Polícia Federal parece não ter sido muito eficaz, visto o problema de novo se repetir e talvez com maior gravidade. O programa "Flávio Cavalcanti" denunciou situação parecida. E as revistas "Realidade" e "Cruzeiro" trouxeram reportagens que configuram bem o problema. Isto sem falar das denuncias claras, explícitas e documentadas de meu bispo, D. Pedro Casaldáliga, em seu livro "Uma igreja da Amazônia em Conflito com o Latifúndio e a Marginalização Social”.

Vou relatar-Ihe dois dias de vida, sobre o particular, aqui na casa Paroquial. Dias 28 de 29 de maio. Só refiro o que sei por conhecimento direto, testemunhado a mim mesmo pelas próprias vítimas.

A partir deste ponto, o ofício de cinco páginas, assinado pelo padre Antônio Canuto, vigário substituto de S. Terezinha (MT), em 30 de maio de 1972, elenca uma série de casos de prisões, em que os gatos e fiscais das fazendas contam com o trabalho da polícia, "capturando os "fugitivos" e levando-os à força de volta para as fazendas. A indagação que fazem é difícil até mesmo para encontrarmos expressões que as traduzam: "Até quando iriam trabalhar só a troco de comida e maleita? Por isto fugiram novamente".

Do relato dos trabalhadores o padre Canuto anota e denuncia a irremediável sentença de morte:

O "gato" simplesmente lhes respondeu que iria mandar levantar um cruzeiro para poderem ir chorar a seus pés, e que se alguém tentasse fugir, a polícia iria caçá-los e de volta traria a roupa e as botas [...] José Rocha trabalhou sozinho. A maleita o derrubou.

No ofício ainda consta o que o padre Canuto chama de "traficados", ou seja, registra a existência do tráfico de pessoas, o trabalho compulsório, fome, morte por malária, doenças gástricas e outras, além dos "trancafiamentos" nas fazendas:

Osvaldo dos Santos, 32 anos, natural de Ipiaú, BA, e Hildê Luciano da Silva, 23 anos, natural de Arraias, GO, foram traficados em Barra do Garças, junto com outros 60 homens pelo "gato" José Vitalino, coadjuvado por José Cantuário, para trabalharem na Fazenda Reunidas. Só após o meio da viagem para S. Félix é que souberam que viriam para a CODEARA. Com 
medo de que algum homem fugisse, os "gatos" foram à frente em S. Félix buscar a polícia dizendo que os peões estariam armando uma revolta. Quando os caminhões chegaram ao porto da Fazenda Suiá, pouco antes de S. Félix, a polícia fez uma busca em todos e peões e não encontrando armas, recolheu facões e canivetes. Os peões reclamaram ao sargento de fome, pois faziam só uma refeição por dia, durante a viagem ao que o sargento Ihes respondeu que o Zé Vitalino iria providenciar. E todos foram encaminhados para o interior do barco que os esperava e foram levados para uma ilha em meio ao Araguaia onde tiveram que passar a noite. Pela meia noite chegou o José Vitalino com algumas latas de sardinha e farinha e retornou a São Félix. Enquanto isto José Cantuário empregava meios de intimidação contra os peões. Empurrava-os, atirava em sua direção.

As denúncias e reivindicações do padre Canuto neste ofício aparecem como registros que resultaram das anotações condensadas de apenas dois dias - "Vou relatarIhe dois dias de vida, sobre o particular, aqui na casa Paroquial. Dias 28 de 29 de maio. [...] testemunhado a mim mesmo pelas próprias vítimas." -, mas que podem ser vistas num tempo dilatado que ignora o sentido dos limites, ainda que histórico. Este tempo denso que alcança o passado e o futuro contém a diversidade das experiências que se encontra na documentação. Essas experiências, associadas à violência e à resistência, são as marcas que pulsam dos registros do acervo da Prelazia por meio dos relatos dos posseiros, trabalhadores rurais, peões e índios. Estes relatos são sua matéria de vida. A memória desse tempo não encerra apenas relatos de acontecimentos, mas histórias que se inscrevem em uma constelação de fragmentos que se tornam um legado trágico, mas de luta, de uma história do trabalho no Brasil.

Finalizo este texto questionando a pluralidade dos significados históricos dos testemunhos, seus diversos usos e interesses para uma construção crítica da memória histórica. O que importa é a busca da linguagem histórica que expresse o seu sentido político a fim de analisar os fragmentos em seu contexto e extorquir do passado, no qual vivem, a violência que encerram e os atualizam no presente. Segundo François Dosse, o filósofo Bergson rompe com a linearidade da cronologia e antecipa uma concepção de tempo fundamental aos historiadores, porque esta "é baseada na concepção de um passado 'contemporâneo' do presente que ele foi”. Nesta abordagem, compreende-se que:

Há o paradoxo da contemporaneidade do passado que retém a encarnação da lembrança dentro de uma imagem-lembrança que não pode se projetar dentro do seu próprio presente, do qual é contemporâneo, mas somente em função do novo presente que o retém como passado. ${ }^{48}$

O trabalho com os testemunhos prioriza essa discussão acerca da noção de tempo e busca analisar as possibilidades de sua atualização no presente, onde adquirem legibilidade, além de problematizar a reflexão sobre o lugar e o tempo do historiador e a sua relação com o lugar e o tempo daqueles que testemunharam, entendendo a história como mediação crítica. Assim, o conhecimento do passado pode se tornar um dos acessos possíveis ao presente ou, de maneira mais incisiva, a partir do nosso tempo o que poderíamos perguntar ao passado?

Recebido em: 19/02/2014

Aprovado em: 02/04/2014

48 DOSSE. Renascimento do acontecimento, p. 88. 